HUOM! Tämä on alkuperäisen artikkelin rinnakkaistallenne. Rinnakkaistallenne saattaa erota alkuperäisestä sivutukseltaan ja painoasultaan.

Käytä viittauksessa alkuperäistä lähdettä:

Alamäki, A., Pesonen, J. \& Dirin, A. (2020). Triggering effects of mobile video marketing in nature tourism: Media richness perspective. Information Processing and Management, 56(3), 756-770. DOI: 10.1016/j.ipm.2019.01.003

PLEASE NOTE! This in an electronic self-archived version of the original article. This reprint may differ from the original in pagination and typographic detail.

Please cite the original version:

Alamäki, A., Pesonen, J. \& Dirin, A. (2020). Triggering effects of mobile video marketing in nature tourism: Media richness perspective. Information Processing and Management, 56(3), 756-770. DOI: 10.1016/j.ipm.2019.01.003

The final publication is available online: https://doi.org/10.1016/j.jpm.2019.01.003

(C) 2020. This manuscript version is made available under the CC-BY-NC-ND 4.0 license http://creativecommons.org/licenses/by-nc-nd/4.0/ 


\title{
Triggering effects of mobile video marketing in nature tourism: media richness perspective
}

\author{
Ari Alamäki, Haaga-Helia University of Applied Sciences, Helsinki, Finland \\ Juho Pesonen, University of Eastern Finland, Joensuu, Finland \\ Amir Dirin, Haaga-Helia University of Applied Sciences, Helsinki, Finland
}

\begin{abstract}
In this study, we aim to understand the video as potential behavioral triggering means. Therefore, we have applied the theory of triggers and media richness to learn about the triggering efficiency of mobile marketing videos on participants' behavioral intentions. In our experiment, we have employed three distinct test groups to carry the experiment, each group comprising of 41 student participants. We discovered that different kinds of videos based on media richness theory have quite similar effects on triggering behavioral changes. However, the mechanic of why triggers happen was different for each video. The results also show that most important reason for triggering any kind of effects was the consumer position in information search process. In addition, the instructionally designed videos were able to create affective triggering impact, as the more participants liked the video, more it affected their participation intention and recall scores. This study extends the media richness research by demonstrating that the effect of media richness can vary within the technically similar videos as they form different logical connections of non-verbal visual cues related to video's storyline.
\end{abstract}

Keywords: media richness, mobile, video marketing, triggers, nature tourism, service marketing

\section{Introduction}

How much marketing and digital communication affect our behavioral intentions is an interesting issue to investigate. Marketers around the world try to aim the correct message at the correct people at the right time in order to trigger a response - preferably a purchase or action. Traditionally, the 
firm-customer exchange process has been considered as a series of interactions between service providers and consumers (Gupta \& Zeithaml, 2006). Lately, digital marketing communication has gained increased attention, and every company is facing the question of how it can maximize the potential gains from digital marketing channels (Karjaluoto, Mustonen \& Ulkuniemi, 2015). This has resulted in the increased importance of effective marketing communications for defining which firms succeed and which ones do not (Cornelissen, 2004). However, effective marketing communication can be difficult to accomplish, especially in service marketing, such as tourism (Pesonen \& Pasanen, 2017). The information search and consumption process in the tourism field is extremely complex, and there is a need for more research on the topic, especially on how media and marketing messages affect tourists' choices (Pesonen \& Pasanen, 2017).

Online videos have become a focal point for marketers. For example, on YouTube alone, users watch more than one billion hours of video material every day (Google, 2017). No matter the source, the statistics show a rapid increase in the amount of video material being consumed online throughout the world. Furthermore, this consumption is being done increasingly on mobile devices, which have become significant end-terminals for online content consumption (Chen et al., 2017). Despite the importance of mobile videos in marketing, research on their influence on consumer behavioral intention is scant.

This study is based on the service marketing literature and investigates how different kinds of marketing messages, promoted through videos, trigger behavior changes in consumers. From the marketers' perspective, it is important to know how to develop video content according to the potential consumers and what factors trigger media effects. Digital content, such as social media posts, blog articles, webinars, or videos, is usually produced by either other consumers or firms, and brand owners exert little control over the consumers' content consumption and sharing (HennigThurau et al., 2010; Lamberton \& Stephen, 2016). The primary focus of firm-generated digital content is to advise or assist consumers with their decision-making (Kumar et al., 2016).

However, it remains unclear what kinds of videos affect the information search and purchasing behavior and why. Earlier literature suggests that attitudes affect intention, which affects behavior (Sheeran \& Webb, 2016). There are also gaps between these concepts, meaning that even if people intend to do something, they do not necessarily do it (Sheeran \& Webb, 2016). Although a few studies have been conducted on this topic (e.g., Puccinelli, Wilcox, \& Grewal, 2015; Huertas, 2018), it remains surprisingly under-researched when we consider its importance to marketers. Marketers need to think about the kind of message that they are using as well as how different kinds of people will process the information. The same message can have different outcomes depending on who is 
receiving it (Watzlawick, Beavin \& Jackson, 1967). The media richness theory (Daft \& Lengel, 1986; Sun \& Cheng, 2007) explain how different richness of media affects differently to receivers' understanding as media's capacity to transmit information varies.

This study examined how watching a service marketing video triggers a consumer's behavioral intention and what kinds of consumers are affected most strongly by different kinds of marketing videos. We examined, for example, recall rate, satisfaction, and behavioral intention regarding the service, and how instructive, seductive, and decorative types of video content (Sung \& Mayer, 2012) differed in their effects. We compared which was more important for triggering behavior in marketing communication: who the customer is or the kind of message with which he or she interacts.

Thus, this study contributes to filling the aforementioned research gap concerning the relationship between consumers and marketing video content. This research gap is especially relevant in the field of digital and social media marketing, where the consumption and sharing of videos is becoming increasingly important. For example, Mark Zuckerberg, the founder of Facebook, stated in 2014 that video would be the most important type of media on Facebook in the near future (Miners, 2014).

This paper is organized into five sections, the first being the introduction. The next section provides a review of the related literature. The third section describes the methodology and research settings. The fourth section presents the results. The last section identifies the contribution, theoretical and managerial implications, and limitations of the study.

\section{Related work}

\subsection{Development in service marketing}

In service marketing, service providers make promises about value that consumers can expect— that is, they offer value propositions (Grönroos \& Ravald, 2011). Value propositions, such as mobile marketing videos, are promises, suggestions, and projections of practices relating to how consumers can co-create value with service providers in integrating resources (Skålén, Gummerus, Koskull, \& Magnusson, 2015). Advancements in information processing and management are constantly creating new possibilities for enriching consumer interaction (e.g., Del Vecchio, Mele, Ndou \& Secundo, 2017; Kim, Jung, \& Park, 2018). Thus, service businesses are increasingly seeking new means to improve their marketing and sales activities in online channels. Consumers have also become active subjects in digital channels (Rust \& Huang, 2014), influencing the means of service marketing. 
Although the rapid expansion of digital tools and channels have developed service marketing, it has also made consumer behavior more complex and powerful (Verhoef, Kannan, \& Inman, 2015; Nguyen \& Le Nguyen, 2018). In turn, this has increased the importance of reputation management in companies (Peetz, de Rijke, \& Kaptein, 2016). Furthermore, the boundaries between traditional and digital service marketing are merging (Brynjolfsson, Hu, \& Rahman, 2013), and consumers create their own unique customer journeys within a mixture of traditional and digital channels (Lemon $\&$ Verhoef, 2016). Therefore, it is important for service companies to respond to changing consumer behavior by recognizing new digital triggers that affect the consideration or selection of a favorable service provider.

\subsection{Triggers and service provider selection}

The important goal of digital service marketing is to trigger consumers' behavior that will foster a positive relationship with the service provider at each phase of the customer journey (e.g., Lemon \& Verhoef, 2016). A trigger is a factor that influences a change in consumer behavior by creating a reason to begin to consider switching or selecting a certain service (Roos, Edvarsson, \& Gustafsson, 2004). A situational trigger affects a consumer's personal life or environment, whereas a reactional trigger occurs when a consumer is considering, purchasing, or using a service (Gustafsson, Johnson, \& Roos, 2006). Instrumental triggers include time-, cost-, and frequency-related factors, unlike affective triggers, which are related to feelings, such as stress, safety, and autonomy (Skarin, Olsson, Roos \& Friman, 2017). Thus, some triggers are created by intentional or unintentional actions of service providers that are focused on cognitive, emotional, and behavior-based processes (Edvardsson \& Strandvik, 2000). Other triggers just occur in a consumer's life through their environment. However, all triggers, whether they are intentional or unintentional, influence consumers' perceptions and their buying behavior. Marketing videos, as means of digital marketing, can trigger consumers instrumentally by communicating service content, price information, benefits, schedule, and other service details. They can also communicate affective triggers, such as joy, safety, security, health, and emotional experience.

To understand the triggering process in consumer behavior in digital service marketing, it is essential to distinguish between the marketing message and the consumer receiving it. Thus, it is important to examine the attributes that define the effectiveness of mobile video content and consumer-related cognitive, emotional, and behavior-based factors. 


\subsection{Individual characteristics and effectiveness of marketing information}

According to previous literature, individuals exhibit many different behavioral patterns in digital environments, and individual characteristics influence consumer behavior (Hallikainen, Alamäki, \& Laukkanen, 2018). Thus, the attributes of marketing messages are insufficient for explaining the effectiveness of marketing; consumers' characteristics must also be understood. As Watzlawick, Beavin, and Jackson (1967) stated, "every communication has a content and a relationship aspect such that the latter classifies the former and is therefore a metacommunication" (pp. 54). That is, individuals can have different relationships to the same information content.

Different values drive the consumption of products and purchase of services by creating different relationships to consumers. Sheth, Newman, and Gross (1991) clarified that in the theory of consumption values, functional, conditional, social, emotional, and epistemic values drive consumer buying behavior, and individuals differ from each other concerning those values. Similarly, the learning psychology literature (Piaget, 1985; Vygotsky, 1978) emphasizes the constructive concept of learning, which shows that humans process new information on the basis of their prior understanding and experiences. In other words, the consumer's mind is not an empty receptacle into which marketers can simply pour their marketing messages. In addition to individual value preferences and cognitive capabilities, many other factors contribute to marketing effectiveness. They can be, for example, demographics (Grant \& O'Donohoe, 2007), psychological benefits, desires, or novelty seeking (Lin \& Huang, 2012), or prior experiences (Vakratsas \& Ambler, 1999).

\subsection{Interrelationship of cognitive and emotional information}

It is difficult to find a relationship between recalling marketing information and sales effectiveness (Lodish et al. 1995). This means that if a consumer remembers marketing information, it will not necessarily directly trigger the consumer's behavior. Additionally, an advertisement may influence consumer behavior even if the consumer does not recall the content or details of the advertisement when making purchase decisions (Heath, Brandt, \& Nairn, 2006). However, this finding does not neglect the importance of cognitive processes concerning video marketing or any marketing method. Consumers need to recall and understand things related to the details of services when they make decisions. Several studies have shown that the emotional design facilitates cognitive learning and user 
experience (e.g., Dirin, Laine, \& Alamäki, 2018; Mayer \& Estrella, 2014; Plass, Heidig, Hayward, Homer \& Um, 2014). The research of Lazarus (1991) evinced a strong interrelationship between rational appraisals (cognitive dimension) and emotional reactions (emotional dimension) in human behavior. It is important to note that cognitive processing is not necessarily conscious, but most human actions are directed by subconscious mechanics (see Sweller, Ayres \& Kalyga, 2011). In addition, the cognitive load theory (Bannert, 2002; Mayer, 2009; Sweller, Ayres, \& Kalyuga, 2011) explains how human's limited cognitive capacity in processing novel information might slow down remembering.

Several studies have shown that emotional information creates more effective results than rational cognitive information (e.g., Heath et al., 2006; Song, Dai, \& Wang, 2016; Vakratsas \& Ambler, 1999). Berger and Milkman (2012) studied the sharing of online content to understand which factors make it go viral. They determined that having an emotional reaction while reading an article causes consumers to want to share the content with others. In general, they found that positive content is more viral than negative content, and content that evokes high-arousal emotions is more viral among consumers. However, Young (2004) stressed that emotion is not a property or concrete object in the marketing content that just flows out to the minds of consumers. Consumer behavior is a complicated process, as cognitive experiences have a crucial role in affecting an emotional reaction or flow (Lazarus, 1991). One of the factors affecting cognitive experiences is the media richness, as richer media potentially conveys richer information, such as both verbal and nonverbal messages (Salomon, 1979; Daft \& Lengel, 1986).

\subsection{The role of media richness in generating media effects}

Video is a multimedia presentation (Mayer, 2009). Lim \& Benbasat (2000) state that multimedia as a rich presentation conveys semantically rich information by using a wide range of symbolic systems. Their research shows that multimedia conveys nonverbal messages and facilitates understanding, making information less ambiguous. Unlike multimedia, text, audio and pictures alone do not make logical connections between symbolic systems, and cannot convey the meaning of conditional events or causes (Salomon 1979; Lim \& Benbasat, 2000). Thus, multimedia presentation can convey and communicate both factual and equivocal information (Liu et al. 2009).

The concept of media richness (Daft \& Lengel, 1983, 1986) provides a theoretical framework for understanding the potential benefits that consumers gain from different types of media and how much a specific medium is able to deliver in terms of information and emotional cues. Media richness as 
the objective property of media indicates how much a media can facilitate shared understanding within a time interval (Sun \& Cheng, 2007). Although media richness may improve communication, it does not necessarily have a causal connection to the actual performance of communication (Dennis \& Kinney, 1998), as contextual and situational variables also affect the demands of communication. Mayer (2009) showed that the processing of spoken words in connection with animated presentations provides more effective recall scores than processing printed words on animated graphics. Dennis and Kinney (1998) concluded that when seeking to improve communication performance using media, the goals and tasks affect the selection of proper media more than media richness does. The media content can make a difference within the same richness of media (e.g., Fiorella \& Mayer 2016; Ho, Chiu, Chen, \& Papazafeiropoulou, 2015; Sundar, 2000). Additionally, the media selection can affect users in different ways in the long run (e.g., Tan, Tan, \& Teo, 2012). Furthermore, there is no causal connection between the media platform and changing customer behavior, similar to instructional media, which does not directly cause learning, as the learning content and instructional methods are what affect the learners (e.g., Clark, 1994; Fiorella \& Mayer, 2016). Hence, YouTube, Facebook, Instagram, and other digital platforms that deliver content do not create media effects; rather, they provide infrastructure for consuming content and collaborating. It is the content that is consumed that creates the effects.

\subsection{Summary of the literature review and research questions}

The literature review shows that consumer behavior has become more complex, interactive, and powerful in digital channels due to the latest advancements in information technology (e.g. Rust \& Huang 2014; Nguyen \& Le Nguyen, 2018). Additionally, videos have a crucial role in digital marketing communication, but minimal research exists on digital videos and their effects on consumer behavior (Huertas, 2018). Earlier literature suggests that individual characteristics, emotional reactions and media richness influence the media effect (e.g. Watzlawick, Beavin \& Jackson 1967; Sun \& Cheng, 2007; Song, Dai, \& Wang, 2016). Although several studies have been conducted on the adoption and use of digital media (Verhoef, Kannan, \& Inman, 2015), few studies have actually compared different kinds of digital marketing messages and how they trigger consumer behavior. This is something that digital tools and channels have made considerably easier during the past few years and that open up new opportunities for marketers and researchers.

The present study is aimed at filling the research gap concerning the relationship that consumers have to marketing video content. In digital service marketing, it is essential to understand which attributes 
affect service provider selection and how they trigger consumer behavior. Thus, it is essential to first understand how the consumption of video material triggers consumers' behavioral intention and the consumers who are affected the most. Thus, the main goal of this study was to examine which is more important: having the right message or the right audience. The findings of the literature review led to the development of the following research questions:

1) How does media richness differences in video content trigger changes in tourist behavior?

2) What affects the triggering of behavioral changes among different types of videos?

3) How do consumers' individual characteristics and phase of information search process compare with respect to video types in triggering changes in behavioral intention?

\section{Research methods and data}

\subsection{Three approaches to digital video content design}

We studied the relationship between consumers and marketing videos and the differences among three visual modifications. According to the media richness theory (Daft \& Lengel, 1986; Sun \& Cheng, 2007), richer media can convey multiple cues and help to facilitate understanding. Video as a form of multimedia can convey both verbal and non-verbal cues (see e.g. Lim \& Benbasat, 2000; Liu et al. 2009). We modified visual cues and logical connection of video attributes by changing $30 \%$ of video clips in the same storyline. Thus, to modify the videos, we adapted Sung and Mayer's (2012) research on the effects of graphics in learning on online lessons. First, the instructive graphics had to match the intended instructional goal for easing the learning process. The instructive video content instructed the service details; thus, it presented the actual details of a canoeing trip, such as a guide briefing customers, canoeing on the lake, sitting around a campfire, and visiting a vantage point. Second, the seductive graphics and clips were aimed at eliciting users' emotions, as the nature of outdoor activities, such as canoeing, evokes similar emotions. Thus, the seductive video content included wild animals, such as a duck swimming and seeking food in a lake, geese and swans swimming, and geese flying or landing on the water at a bay. Third, the decorative graphics included cognitively and emotionally neutral visual content. Nature was the main focus of our video clips and experiment, and it was not considered a value proposition. In the experiment, the decorative videos presented only trees and a blue sky, zoomed and recorded upwards. Their visual message was neutral, and they neither instructed nor elicited an emotional response. 


\subsection{Participants and design}

The participants were 123 undergraduate students pursuing a business information technology degree program in Finland. The selection criterion was that participants represent as much as possible potential real-life customers of outdoor tourism services. The participants' socio-demographics represented the tourism segment of activity enthusiasts, who are young males and females who prefer outdoor activities and experiencing peacefulness in nature (Nepa, 2017). Over 43\% of participants represented different nationalities other than Finnish. Although the research goal was to understand videos and consumer behavior as a phenomenon, not to generalize findings to outdoor tourists, the selection of participants among potential consumers increases the trustworthiness of the findings. The instructive, seductive, and decorative videos were each shown to groups of 41 participants, resulting in total of 123 participants. The group size was in line with other similar multimedia studies that had 30-60 participants, on average, per group (e.g., Fiorella \& Mayer, 2016; Mayer \& Estrella, 2014; Sung \& Mayer, 2012). The participants' socio-demographic profile is presented in Table 1.

Table 1. Participants' socio-demographic data

$\underline{\text { Gender }}$

Female

Male

Age $\%$

Below 20

21-30

Over 30

8.1

Nationality

$\underline{\%}$

Finnish

Other European

Asian

American

African

Other

How often do you do outdoor activities (hiking, kayaking, canoeing, mountain biking, or related)?

Never

Once a year

Every 6 months

Monthly

Weekly

Note: $\mathrm{N}=123$ 
Student samples are often used in academic research in various fields, including psychology, social psychology (Payne \& Chappell, 2008), business research (James \& Cohen, 2004), political science (Druckman \& Kam, 2011), and marketing (Yavas, 1994). Yavas (1994) suggested that the use of students is appropriate in scale development as well as in modelling attitude-behavior relationships. We wanted to control as many factors as possible to ensure that changes in behavioral intention were mostly because of who the respondents were and the kind of video that they watched. A classroom experiment allowed us to reach this goal. Moreover, the sample of 123 students was well in line with the sample sizes used in earlier research (James \& Cohen, 2004; Sung \& Mayer, 2012). The goal of this research was not to generalize the findings but to determine how various concepts are connected and what kinds of relationships exist between factors. A student sample was well-suited to this kind of research (Yavas, 1994), and the sample size was adequate for the analysis methods used, despite the limited explanatory power of the models used in this study (Green, 1991).

\subsection{Design and modification of marketing videos}

We employed a variety of instructive, seductive, and decorative video content. First, we created one marketing video according to instructive principles, and it formed the basis for the two other modified videos (Fig. 1). The primary goal of the videos was to inform users about service content and encourage consumers to purchase a one-day canoeing trip in a Finnish national park. All videos and related video materials had the same context (outdoor tourism activities and nature) from the beginning to the end.

All videos were 2 minutes and 19 seconds long, and they included 15 different video clips in the same order. The text or caption (Appendix A), which was the same in all videos, was displayed in the same place in all modified video clips. In total, 5 out of 15 video clips were modified, and the materials were captioned. Thus, we modified $30 \%$ of the 15 video clips, which means that all test groups saw 5 different and 10 common video clips. The modified videos covered 85 seconds $(61 \%)$ of the total 139 -second length of the video presentation; hence, $39 \%$ of the total time comprised common video content presented to all participants. 

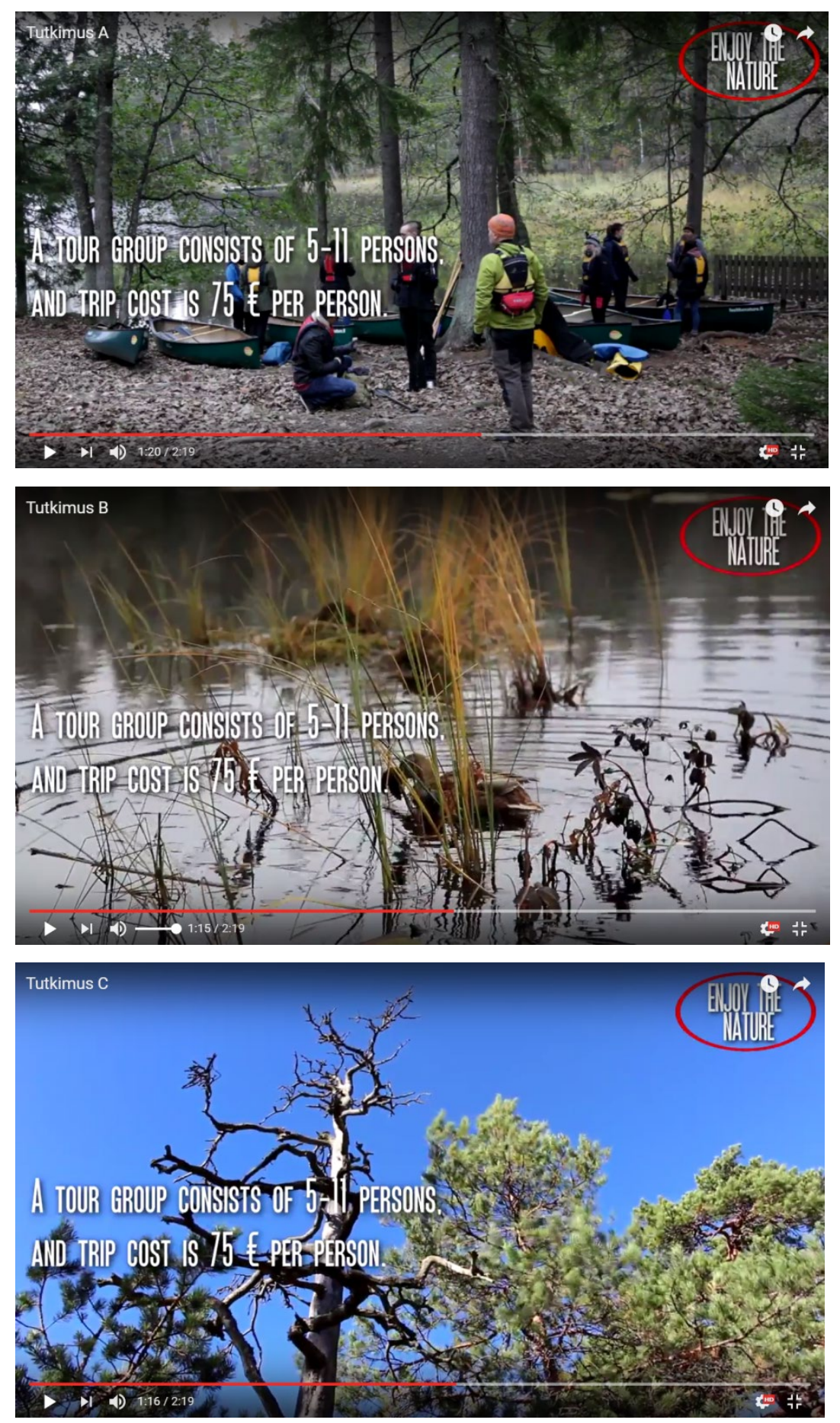

Fig. 1. Examples of instructive (A), seductive (B), and decorative (C) video clips with the same caption.

The videos were recorded during a real canoeing trip with a tourism company that provides and markets similar canoeing trip services on its e-commerce site. The seductive and decorative video clips were recorded elsewhere, but they represented nature topics and had the same context. All video clips represented an authentic, natural environment (context), but they differed from each other in 
terms of their relevance for illustrating a canoeing service. We had to consider carefully the end-user perspective while planning and designing the marketing videos. Every video had to feel like a real marketing video in order for users to take it seriously in the test situation. Our initial plan was to create videos that were purely instructive, seductive, and decorative, as in Sung and Mayer's (2012) study, where the graphics only changed in connection to the same text. However, from the user perspective, seductive and decorative videos did not work, as the caption described the service details of canoeing; thus, the videos presented "wrong" graphics from the beginning to the end. For enhanced trustworthiness, we decided to change the experimental design; although the results of the videos would probably have differed significantly from each other, especially in terms of satisfaction, the user experience would have been artificial or false. Thus, instead of showing the three students groups completely different videos, we decided to modify $30 \%$ of the graphics for each video. In one video, $30 \%$ was instructive content, in one video seductive content and in one video decorative content. There were no music or sounds in the videos. The final test videos were uploaded to YouTube, and the researchers created a TinyURL and QR code. The test users either typed the TinyURL or scanned the QR code to access the videos in the experiment.

\subsection{Measures}

Pre- and posttest questionnaires were administered. The pretest questionnaire was handed out to the participants on paper, and they filled it out before they watched the video. It comprised 10 multiplechoice questions. The first three questions concerned age, gender, and nationality. The remainder of the questionnaire consisted of multiple-choice items concerning their participation in outdoor activities (hiking, kayaking, canoeing, mountain biking, or related), how they viewed themselves as travelers, and whether they had purchased tourism services online (other than flight tickets).

The pretest also contained three multiple-choice questions measuring transactional intention to participate in or purchase a canoeing trip in Nuuksio National Park, which was the target canoeing service presented in the videos. We adapted the transaction intention measures of Pavlou and Gefe (2004) for this study. Those three questions were also asked in the posttest questionnaire to measure the videos' effects concerning the behavioral change of transaction intention. The questionnaire included the following transaction intention questions rated on a 5-point Likert scale $(5=$ strongly agree, 1 = strongly disagree): "At this moment, I am interested in buying a canoeing trip in Nuuksio National Park"; "If I had the chance, I would like to participate in the guided canoeing trip in Nuuksio National Park"; and "It is likely that I will go canoeing in Nuuksio National Park in the next two years." 
We adapted Sung and Mayer's (2012) measures in designing the recall and satisfaction tests. The following open-ended question was used to test recall: "Please write down all service details and facts presented in the video. You can write down key words, but if you don't remember the key words, you can write sentences explaining the meaning of the service details and facts. You have $5 \mathrm{~min}$. to record your answer." The purpose of the recall test was to measure how much of the service details presented in textual format (caption) in the videos the participants remembered (Appendix A) and if different video content presented simultaneously influenced their recollection. The caption in the videos included 25 key points, such as the length of the total canoeing trip, canoeing time, price, departure details, size of the group, free lunch and its details, and other service content. Thus, one could earn a maximum of 25 points, and a participant received a point if he or she mentioned verbatim or a synonymous term in his or her written answer. The recall test did not measure understanding-only memorization of information relating to the service.

The satisfaction test measured participants' emotional orientation toward the videos. We adapted Sung and Mayer's (2012) measures to suit the context of this study, and the satisfaction rate was measured on a 5 -point Likert scale $(5=$ strongly agree, $1=$ strongly disagree). The questionnaire included the following four questions: "I felt that the video material impacted positively my feelings"; "I felt good when I viewed this video material"; "I think the visual content of this video material was interesting"; and "I enjoyed learning about the canoeing trip details from this video material." We also measured the quality of the video material using four variables: "I enjoyed learning about the canoeing trip details from this video material (Learning)"; "I think the visual content of this video material was interesting (Visual Content)"; "I felt good when I viewed this video material (Feeling Good)"; and "I felt that the video material impacted positively my feelings (Emotional)."

\subsection{Procedure}

The test videos were designed for smartphone use. For example, the font size of the text was optimized for mobile usage. The experiment took place in classrooms, where participants watched one of the three videos on their own mobile devices. The researchers provided a smartphone to any participant who did not have one or could not use their own device. The use of mobile devices is rapidly growing, and most potential consumers will view marketing videos on their mobile devices. Thus, selecting a mobile device as the end-terminal simulates a real usage situation. It was also easy to arrange this because all participants had their own smartphones and the university where the experiment took place provides free Wi-Fi access. There were 20-25 participants at the same time in 
the classroom where the experiment was taking place. They were informed about the experiment in advance.

The participants were randomly assigned to different groups by handing different video addresses to them in pre-selected order. The video addresses (TinyURL and QR code) were printed on the posttest paper sheet. At the beginning of the experiment, the researcher explained the test procedure and verified that everyone present wanted to participate and had a smartphone to use. Then the researcher distributed the test material, and the participants first answered the research items of the pretest. Subsequently, they were allowed to continue by turning over the paper, where their special video address was printed. They accessed the YouTube video address and watched the video, which did not have audio. The participants answered the research items of the posttest right after watching the video. The researcher supervised the procedure of the experiment, which took 30 minutes including the briefing, pretest, watching of videos, and posttest.

\subsection{Data analysis}

The data set consisted of 123 fully completed questionnaires. The data analysis was conducted with SPSS 21. First, the student groups were compared to determine if there were any differences between them that might affect the results.

A paired samples t-test was conducted on interest in purchasing a canoeing trip, interest in participating in a canoeing trip, and likelihood of going canoeing in Nuuksio National Park to analyze how watching the videos affected these variables for each participant. A paired samples t-test computes the differences between the values of two variables for each case in the data and tests whether the average differs from 0 . The three aforementioned dependent variables together with recall score were used as dependent variables in further analyses.

Subsequently, the videos were compared to assess the four dependent variables and examine if different videos had different effects on recall score and interest in the tourism services. This analysis was conducted using one-way analysis of variance (ANOVA). In addition, post-hoc Tukey tests were conducted for each pair-wise comparison with alpha set at 0.05 . We also ran a correlation analysis to understand the connections between video quality, recall score, and change in consumer preferences. We then examined how the videos differed regarding their quality and how video quality affected consumer behavior. 
In the last phase of the data analysis, regression models were used to analyze the most influential factors in explaining changes in consumers' behavioral intention. Ordinal regression was used as the predictor variable was measured as successive categories. Ordinal logistic regression is the best tool for predicting the probability of an interesting outcome when the outcome is measured on an ordinal scale (Andereck \& Nyaupane, 2011; O’Connell, 2006).

\section{Results}

\subsection{Group differences in demographic characteristics and interest variables}

The groups were based on student classes; thus, they were selected randomly. Nevertheless, it was crucial to analyze possible differences among the groups that might affect the results. Based on the ANOVA of variables connected to interest in canoeing in Nuuksio National Park and chi-square tests with $\mathrm{p}<.05$ on demographic variables, no statistical differences were found among the three groups. They were similar regarding background variables and other variables, irrespective of the video they watched. Thus, we were able to focus on the video as the change agent.

\subsection{Effects of watching canoeing videos}

In the first part of the data analysis, we compared the whole sample to see how watching the video changed the watchers' behavior. The paired samples t-test results (Table 2) indicate that watching the videos increased participants' interest in the canoeing service as all means after watching the video are greater than those before. The only statistically significant change in behavioral intention $(\mathrm{p}=$ 0.036) concerns interest in purchasing a canoeing trip in Nuuksio National Park, meaning that after watching the videos, the participants were generally more interested in purchasing the canoeing trip.

Table 2. Paired samples t-tests on before and after watching the videos

\begin{tabular}{|c|c|c|c|}
\hline & $\begin{array}{l}\text { Mean } \\
\text { before } \\
\text { video (M1) }\end{array}$ & $\begin{array}{l}\text { Mean } \\
\text { after } \\
\text { video } \\
\text { (M2) }\end{array}$ & $\begin{array}{l}\text { Paired } \\
\text { Differences } \\
\text { (M2 - M1) } \\
\text { (SD) }\end{array}$ \\
\hline $\begin{array}{l}\text { At this moment, I am interested in purchasing a canoeing trip in } \\
\text { Nuuksio National Park. [Purchase Intention] }\end{array}$ & 2.37 & 2.56 & $0.20(1.02)^{*}$ \\
\hline $\begin{array}{l}\text { If I had the chance, I would like to participate in the guided canoeing } \\
\text { trip in Nuuksio National Park. [Participation Intention] }\end{array}$ & 3.15 & 3.25 & $0.10(0.76)$ \\
\hline $\begin{array}{l}\text { It is likely that I will go canoeing in Nuuksio National Park in the next } \\
\text { two years. [Likelihood to Action] }\end{array}$ & 2.64 & 2.76 & $0.12(0.83)$ \\
\hline
\end{tabular}

Note: $\mathrm{N}=123, * \mathrm{p}<0.05, * * \mathrm{p}<0.001$ 
We also wanted to see how personal attributes affected interest in the service before watching the video. Using chi-square tests, we found out that women were more interested in buying a canoeing trip than men $(\mathrm{p}=0.023)$, that foreign respondents were more likely to participate in the guided canoeing trip and go canoeing in Nuuksio National Park than Finnish respondents $(p=0.005)$, and that the more often a person does outdoor activities, the more likely they would be to go canoeing in Nuuksio within the next two years. We also looked at correlations between behavioral intention scores before the videos and how the responses changed after watching the videos. We identified statistically significant negative correlations in interest $(\mathrm{r}=-0.459, \mathrm{p}<0.01)$, participation $(\mathrm{r}=-0.374, \mathrm{p}<0.01)$, and likelihood of going canoeing $(\mathrm{r}=-0.411, \mathrm{p}<0.01)$. This means that the less interested a person was before watching the video, the more likely it was that their interest grew because of the video. At the same time, the more interested a person was in canoeing in Nuuksio before the video, the less likely they were to be more interested in canoeing in Nuuksio after watching the video.

\subsection{Effects of videos on recall test scores and interest in the tourism service}

In the second part of the analysis, we examined how watching instructive, seductive, and decorative videos affected participants' interest in canoeing and how well they remembered details from the video (Table 3 ). At the 0.05 level, there were no statistical differences among the three videos in how they changed consumers' opinions or how well participants could recall details from the videos. When looking at effect sizes computed (Table 4) with Cohen's $d$ (Cohen, 1988), we noticed that there was a medium-sized effect between the instructive and seductive videos in creating interest in a canoeing trip in Nuuksio National Park. Medium-sized effects were also identified between the seductive and decorative videos in increasing participants' likelihood of going to Nuuksio National Park in the next two years and between the decorative and instructive videos in likelihood of going canoeing in the future. This meant that these three differences were especially worth investigating further.

Table 3. Mean recall test scores and interest in the tourism service (before and after)

\begin{tabular}{llllllll}
\hline Measure & \multicolumn{3}{l}{ Type of graphics } & \multicolumn{3}{c}{ Sig. } \\
& Instructive & Seductive & \multicolumn{2}{c}{ Decorative } & \\
& Mean & SD & Mean & SD & Mean & SD & \\
Recall score & $\underline{6.15}$ & $\underline{3.41}$ & $\underline{5.63}$ & $\underline{2.60}$ & $\underline{5.78}$ & $\underline{3.16}$ & $\underline{0.74}$ \\
Purchase Intention & $\underline{0.73}$ & $\underline{1.17}$ & $\underline{0.15}$ & $\underline{0.76}$ & $\underline{0.37}$ & $\underline{1.09}$ & $\underline{0.41}$ \\
Participation Intention & $\underline{0.15}$ & $\underline{0.69}$ & $\underline{0.12}$ & $\underline{0.84}$ & $\underline{0.24}$ & $\underline{0.76}$ & $\underline{0.75}$ \\
Likelihood to Action & & $\underline{0.92}$ & $\underline{0.24}$ & $\underline{0.73}$ & $\underline{-0.12}$ & $\underline{0.78}$ & $\underline{0.07}$ \\
\hline
\end{tabular}

Note: $\mathrm{N}=123$ 
Table 4. Effect sizes between videos, Cohen's $d$ values

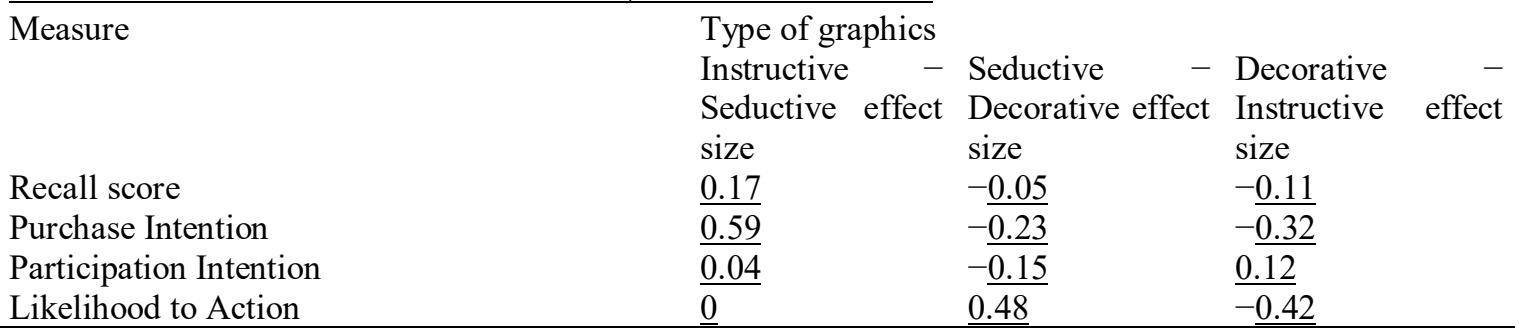

Note: $\mathrm{N}=123$

In the third part of the analysis, we focused on how the feelings participants had when they watched the video affected a change in their intention. We compared the three videos in terms of visual content, learning possibilities, good feeling, and emotions. To determine how video quality attributes affected consumer behavior and preferences among the three videos, we ran a correlation analysis. As we can see from Table 5, there were clear differences among the videos. In the seductive or decorative video, regarding recall score, it did not matter whether a person enjoyed learning the details, thought the visual content was interesting, felt good watching the material, or if the video material impacted emotions positively. However, this was not the case with the instructive video, in which all of these attributes affected recall score. The results show a significant correlation in the instructive video between the change in participating in the guided canoeing trip and enjoying learning the details of the video and positive impact on emotions. These two factors, as well as visual content, all increased the likelihood of canoeing in the future in relation to the instructive video. Regarding the seductive and decorative videos, only one statistically significant correlation was identified. The more interesting a person thought that the visual content of the decorative video was, the more likely they were to participate in the guided canoeing trip in Nuuksio National Park. 
Table 5. Correlation between video quality, recall score, and change in consumer preferences among the different video types

\begin{tabular}{|c|c|c|c|c|c|c|c|c|c|c|c|c|}
\hline & Inst. & Sed. & Dec. & Inst. & Sed. & Dec. & Inst. & Sed. & Dec. & Inst. & Sed. & Dec. \\
\hline $\begin{array}{l}\text { I enjoyed learning the details } \\
\text { of the canoeing trip from this } \\
\text { video material. }\end{array}$ & $0.343^{*}$ & -0.137 & -0.055 & 0.308 & 0.165 & 0.166 & $0.434 * *$ & 0.227 & 0.221 & $0.385^{*}$ & 0.061 & -0.150 \\
\hline $\begin{array}{l}\text { I think the visual content of } \\
\text { this video material was } \\
\text { interesting. }\end{array}$ & $0.352 *$ & 0.090 & 0.271 & 0.233 & 0.044 & 0.256 & 0.244 & 0.260 & $0.442^{* *}$ & $0.366^{*}$ & 0.163 & 0.130 \\
\hline $\begin{array}{l}\text { I felt good when I viewed this } \\
\text { video material. }\end{array}$ & $0.394 *$ & 0.094 & -0.243 & 0.169 & 0.027 & 0.175 & 0.130 & 0.261 & 0.027 & 0.300 & 0.259 & 0.062 \\
\hline $\begin{array}{l}\text { I felt that the video material } \\
\text { impacted positively my } \\
\text { emotions. }\end{array}$ & $0.345^{*}$ & 0.148 & -0.146 & 0.148 & 0.110 & 0.264 & $0.449 * *$ & 0.282 & 0.235 & $0.434^{* *}$ & 0.204 & 0.028 \\
\hline
\end{tabular}

$* \mathrm{p}<0.05$

$* * \mathrm{p}<0.001$ 
In the last part of the data analysis, we wanted to explore how participants' personal characteristics affected the change in customer behavior. We analyzed how age, gender, nationality, and frequency of doing outdoor activities affected behavioral intention. We also included behavioral intention statements before the video as it had been identified as significant in the earlier results. The only statistically significant difference was in gender: men increased their interest in canoeing significantly more than women $(\mathrm{F}=4.056, \mathrm{p}=0.046)$.

We also conducted several ordinal regression analyses to measure how well our independent factors explained changes in behavioral intention. We found that we could explain, even in the best case, $35 \%$ of the change in behavioral intention with our background factors and differences in videos. The strongest factor in explaining the change was always the behavioral intention score before watching the video. Some factors, like how often person does outdoor activities and nationality, seemed to have a small effect, but with such a small data set, this only provides a hint for future research. The statistically significant effects in Table 6 indicate that the higher the behavioral intention score was before watching the video, the less likely the respondents were to score high after watching the video. Finnish and other Europeans were less likely to show increased purchase intention than others. Moreover, the instructive video was more likely to be associated with an increased likelihood of going canoeing than the decorative video, and those who do outdoor activities less than once a year were the least likely to express an increased likelihood of canoeing after watching the video. The R-square statistics are significant, but mostly for the results from the behavioral intention score before watching the video. Wald test is used to find out if explanatory variables in the model are significant (Agresti, 1990). The more Wald test score differs from 0 , the more significant the variables are. 
Table 6. Ordinal regression analysis on how individual characteristics and phase of information search process trigger change in behavioral intention

\begin{tabular}{|c|c|c|c|c|c|c|c|c|c|}
\hline & \multicolumn{3}{|c|}{ Change in Purchase Intention } & \multicolumn{3}{|c|}{ Change in Participation Intention } & \multicolumn{3}{|c|}{ Change in Likelihood to Action } \\
\hline & Estimate & Wald & Sig. & Estimate & Wald & Sig. & Estimate & Wald & Sig. \\
\hline Intention score & & & & & & & & & \\
\hline $\begin{array}{l}\text { before watching } \\
\text { the video }\end{array}$ & -1.177 & 32.394 & .000 & -.687 & 11.878 & .001 & -1.013 & 19.971 & .000 \\
\hline Gender $=$ Female & -.759 & 3.245 & .072 & -.192 & .200 & .655 & .069 & .024 & .877 \\
\hline Gender $=$ Male & $0^{\mathrm{a}}$ & & & $0^{\mathrm{a}}$ & & & $0^{\mathrm{a}}$ & & \\
\hline $\begin{array}{l}\text { Nationality = } \\
\text { Finnish }\end{array}$ & -1.827 & 9.479 & .002 & .137 & .049 & .825 & -.848 & 1.673 & .196 \\
\hline $\begin{array}{l}\text { Nationality }= \\
\text { Other European }\end{array}$ & -2.202 & 8.167 & .004 & -.314 & .160 & .689 & -.909 & 1.185 & .276 \\
\hline $\begin{array}{l}\text { Nationality }= \\
\text { Asian }\end{array}$ & -.420 & .397 & .529 & -.104 & .022 & .883 & -.075 & .011 & .918 \\
\hline $\begin{array}{l}\text { Nationality = } \\
\text { Other }\end{array}$ & $0^{\mathrm{a}}$ & & & $0^{\mathrm{a}}$ & & & $0^{\mathrm{a}}$ & & \\
\hline Age $=$ Under 20 & 1.726 & 3.572 & .059 & 1.049 & 1.290 & .256 & 1.662 & 2.900 & .089 \\
\hline $\mathrm{Age}=21-30$ & 1.093 & 2.587 & .108 & .431 & .375 & .540 & .842 & 1.253 & .263 \\
\hline $\begin{array}{l}\text { Age }=\text { More than } \\
30\end{array}$ & $0^{\mathrm{a}}$ & & & $0^{\mathrm{a}}$ & & & $0^{\mathrm{a}}$ & & \\
\hline $\begin{array}{l}\text { Video }= \\
\text { Instructive }\end{array}$ & -.336 & .591 & .442 & .063 & .019 & .891 & 1.071 & 4.568 & .033 \\
\hline Video $=$ Seductive & -.219 & .250 & .617 & -.035 & .006 & .938 & .901 & 3.301 & .069 \\
\hline $\begin{array}{l}\text { Video }= \\
\text { Decorative }\end{array}$ & $0^{\mathrm{a}}$ & & & $0^{\mathrm{a}}$ & & & $0^{\mathrm{a}}$ & & \\
\hline $\begin{array}{l}\text { Outdoor Activities } \\
=\text { Never }\end{array}$ & -.271 & .148 & .701 & .137 & .035 & .852 & -.777 & 1.076 & .300 \\
\hline $\begin{array}{l}\text { Outdoor Activities } \\
=\text { Once a year }\end{array}$ & -.875 & 1.793 & .181 & -1.038 & 2.294 & .130 & -1.547 & 4.643 & .031 \\
\hline $\begin{array}{l}\text { Outdoor Activities } \\
=\text { Every } 6 \text { months }\end{array}$ & .616 & .994 & .319 & .033 & .003 & .959 & -.704 & 1.046 & .306 \\
\hline $\begin{array}{l}\text { Outdoor Activities } \\
=\text { Monthly }\end{array}$ & .775 & 1.526 & .217 & .213 & .103 & .749 & -.575 & .687 & .407 \\
\hline $\begin{array}{l}\text { Outdoor Activities } \\
=\text { Weekly }\end{array}$ & $0^{\mathrm{a}}$ & & & $0^{\mathrm{a}}$ & & & $0^{\mathrm{a}}$ & & \\
\hline Nagelkerke $\mathrm{R}^{2}$ & 0.382 & & & 0.210 & & & 0.279 & & \\
\hline
\end{tabular}




\section{Discussion and implications}

There is an ongoing discussion in academic research on marketing effectiveness, especially in service marketing. Many are interested in what actually triggers changes in consumer behavior and why (Roos, Edvarsson, \& Gustafsson, 2004). This study examines the topic through media richness theory, which states that verbal and non-verbal cues in media can trigger changes in behavior, especially in learning (Lim \& Benbasat, 2000; Fiorella \& Mayer, 2016). Learning is also important for marketers who aim to communicate with consumers so that consumers get more knowledge about the products and services they are selling. As consumers are spending more and more time on their mobile devices and especially consume more time on mobile video content (Chen et al., 2017; Google, 2017), it has become paramount to understand how and why mobile marketing videos work.

\subsection{The role of media richness in triggering consumer behavior}

The first research question presented in this study is how does media richness differences in video content trigger changes in tourist behavior. We designed three different kinds of mobile marketing videos, one with $30 \%$ of instructive content, one with $30 \%$ of decorative content and one with $30 \%$ of seductive content. All the videos are rich in media, as videos typically are, but nonetheless differed in what kind of message they convey and how. When looking at the results in Table 2 we can see that all the videos had positive impact on respondents' intentions and likelihood to action. The effect was especially significant for purchase intention. When comparing different types of videos we can see that the instructive video seems to be better than seductive video in triggering increase in purchase intention (see Table 3 and Table 4). In addition, seductive video is better than decorative video to trigger increase in likelihood to action, and decorative video is worse than instructive video in triggering changes in likelihood to action. It was also found out that the respondents remembered the details of the videos in similar way no matter what video they watched.

The prior research has shown that richer media does not directly improve media effect (Dennis \& Kinney, 1998), but the effects of cues and their logical connections in similar media are a less studied topic. Based on our best knowledge, there is only few research about this in educational context (e.g. Fiorella \& Mayer 2016). We show that videos differed each other in their capacity to transmit multiple cues and increase personal focus that trigger behavioral intention. We come up this conclusion (see 
Table 5) as the more participants enjoyed and felt that video impacted emotionally to them, their participation intention and recall score improved in watching the instructional video design. In the instructional video, visual cues were most connected to the storyline, and thus created the strongest logical connections between the visual cues of video clips, caption and storyline. We extend the previous media richness research (e.g. Lim \& Benbasat, 2000; Liu et al. 2009) by showing that media richness can vary within the technically similar videos, because media richness is higher if all attributes (e.g. video clips, caption) have logical connection to the storyline and its digital content. In addition, we conclude that media richness of instructionally designed videos relates to their ability to trigger behavioral intention as the visual cues and their better logical connection in the storyline seem to improve media effects. The video as a digital media is more complex than images or text.

\subsection{The videos as instrumental and affective triggers}

The second research question was to find out what affects the triggering of behavioral changes among different types of mobile videos. This contributes to knowing why different types of videos have different kinds of effects on consumers. It is interesting to note that the video quality items we included did not explain changes in purchase intention for any of the three videos (Table 5). Participation intention was increased if respondents perceived the instructive video to provide details in an enjoyable way or impact emotions positively. Participation intention was increased for decorative video the more respondents perceived visual content of the video to be interesting. Likelihood to action was increased for instructive video the more respondents enjoyed learning the details, the more interesting the visual content of the video was, and the more positively the video material impacted their emotions.

This study shows that affective issues and participation intention and recall score are interrelated. That is inline with prior research of cognitive appraisals in emotions (e.g. Lazarus, 1991). Cognitive information processing evokes emotions that affect behavioral intention. Align with Skarin et al. (2017), we have realized that the videos triggered instrumentally, but also affectively the participants. As previously stated, the more participants enjoyed and felt that video impacted them emotionally, the more their participation intention and recall score improved in watching the instructionally designed video. This study shows that the mobile videos, as a growing mean of digital service marketing, can trigger consumers instrumentally by communicating service content, price information, benefits, schedule, and other service details. They can also deliver affective triggers, 
such as emotional experiences. This is align with the earlier research (Heath et al., 2006; Vakratsas \& Ambler, 1999) who showed that emotions play a significant role in marketing communication.

The findings emphasize the importance of the storyline in generating a media effect. The storyline determines the logical connection of video attributes that affects to the media richness (cf. Daft \& Lengel, 1986; Sun \& Cheng, 2007). The storyline is an audio-visual narrative of the message that is communicated by combining different video attributes. We found that changing $30 \%$ of visual cues (video clips) in the same storyline did not make a significant difference in general level as all the videos had positive impact (Table 2). All test groups saw 5 different and 10 similar video clips. In other words, $67 \%$ of similar video content comprising $39 \%$ of the time slot is sufficient for creating a similar marketing message for receivers in general level. However, as before mentioned, we found that the mechanic of why triggers happen was different for each video. This means that better media richness improved the effect of similar storyline. That finding strengthens our conclusion that stronger logical connection between video attributes, such as visual cues and storyline improves media effect.

The findings differ in terms of attributes from the research of Sung and Mayer (2012), who found a more significant difference between relevant and irrelevant graphics in cognitive measures. However, they studied text and graphics, whereas we researched video material that differ in terms of media richness. This difference points out that video material differs from visualized textual material in creating media effects.

\subsection{Videos trigger potential consumers to move on the customer journey}

The third research questions examines how consumers' individual characteristics and phase of information search process compare with respect to video types in triggering changes in behavioral intention. From the ordinal regression analysis in Table 6 we can see that the most significant factor constantly explaining changes in intention and likelihood to action is intention score before watching the video. This means that the lower the intention score before watching the video was, the more likely the score was to increase. Finnish and other European respondents were less likely to demonstrate increase in purchase intention than other respondents. Instructive video was more likely to increase likelihood to action compared to decorative video and respondents doing outdoor activities once a year were less likely to increase likelihood to action than those who do outdoor activities weekly. These results supports the research of Vakratsas and Ambler (1999), who stated that experience is the third significant construct in analyzing the effects of advertisements. In our study, experience decreased the media effect. 
The finding at Table 6 indicates that the videos are able to trigger non-prospective customers to prospective customers, and thus transit them forward on their customer journey. This is something that has not been accounted in earlier studies and show the importance of understanding the complete information search process for each tourist. We call this as the transition of their position on the customer journey, as the videos were able to move less interested participants from the phase to another. This finding contributes to the literature on the customer journey (e.g., Lemon \& Verhoef, 2016; Venkatraman et al., 2015) indicating that recognizing a consumer's position on the journey is important in triggering consumer behavioral intention by the videos. These findings also contributes to the literature of AIDA-theory (e.g. Fiore et al. 2005; Yeh et al. 2017) showing that behavioral intention towards interest of marketed services can be triggered by the videos. We conclude that the media effect happens when the video is able to create relationship between the consumer and the video content. This is essential finding for marketing video design, as the similar video content resonates differently in different consumers based on the phase of the consumer journey. This is in line with the communication research of Watzlawick et al. (1967), which emphasized the importance of the relationship between the receiver and the content in effective communication.

Triggering is an endeavor to change orientation of consumers towards selected services. The orientation changes if consumer feels that the triggering video content provide additional value or create emotional experiences to them. Thus, it is able to meet the existing mental models of consumers, and moves them forward (or probably sometimes backwards) in the customer journey. This study revealed that the service demonstration videos used in this study transferred less interested consumers to interested, but did not necessary transfer already interested consumers to the next phase. We conclude that those consumers require different value proposition (see e.g. Skålen et al 2015), risk reductions (see e.g. Hautamäki \& Alamäki, 2017) or other types of messages in a trigger, and thus different storyline with relevant video graphics, audio and possible text in the videos.

\subsection{Practical implications}

For practitioners, our findings show the importance of recognizing how the relationship between consumers and video content is created. The results also show that different kinds of videos should be used in different parts of the customer information search process, depending on how close they are to purchasing intention. Our findings suggest that the videos affectively trigger consumer behavior if visual cues (e.g., video clips) create logical and strong connection to the storyline and its content. This improves their media richness in conveying non-verbal messages such as service experiences. 
In addition, this study points out that a video's storyline is more important in creating media effects than single attributes of a video.

Some of these results can be used to more effectively design mobile video marketing. If the goal of the video is to increase likelihood to action, the video should contain instructive content, and have a positive impact on emotions, as well as tell about the details of the product or service sold in an enjoyable way. If the goal is to increase purchase intention, the best would be to use instructive content with real customer experiences from value co-creation. For triggering participation intention changes decorative content with interesting visual material or instructive content with enjoyable information about the details or positive impact on emotions would be the best starting point.

\section{Conclusions, limitations and future research}

This study has extended the previously defined media richness and trigger theories through demonstrating real experiments with the test groups. In our study, we have identified and elaborated that service demonstration videos can be efficient to those participants who are less interested and have less experience on the marketed service. Thus, they are effective on the early phases of information search process on the customer journey. In addition, we found that the instructionally designed videos created correlation between positive emotions, stronger participation intention and better recalling of content. In other words, more the participants liked the video, more it influenced to their intention and recalling. In our study, the video is considered as an instrumental and affective triggering medium to those participants who have some uncertainty on their selections. This indicates that stronger logical connection of visual cues to the storyline and service content improved media effect. Hence, we found that richer media affected positively to the behavioral intention in our case. For practitioners, it is more important to reach the right audience with the right storyline than just to design high-quality but generic video content. Especially understanding the phase of the purchasing process for each individual consumer is important.

The limitation of this study is that we did not modify the storyline, only $30 \%$ visual cues, and thus it is a function of method. Although, it did not cause clear effect between video designs, it provided us more understanding about the role of media richness within the similar storylines of videos. However, the results of this study show that the media effect of videos is a complex phenomenon and required extensive investigation. This issue leads us for further study on the relationship of visual cues and storyline, and their logical connections - with stronger modification of storyline. In addition, 360 videos and virtual reality (VR) video applications bring interactivity that is a new attribute to the 
media richness debate. This study shows that individual marketing videos typically have a limited impact on consumer behavior. Even if there is an impact, it is dependent both on the video content and who is receiving it. We suggests researchers to study what kinds of digital triggers are needed in winning new customers in the different touchpoints of their information search process on the customer journey. Hence, we need more research how triggers actually lead into intentions and thus actions.

\section{Acknowledgments}

This study was funded by European rural development fund and Helia-foundation. We thank the anonymous reviewers for their constructive and helpful comments. 